Case Report

\title{
DEVELOPMENTAL DELAY IN CHILDHOOD CATARACT: A CAVEAT MARINESCO-SJÖGREN SYNDROME
}

\author{
Rathika D. Shenoy ${ }^{1}$, Deepthi R.V. ${ }^{2}$, Nutan Kamath ${ }^{3}$ \& Sumana J. Kamath ${ }^{4}$ \\ ${ }^{1}$ Professor, ${ }^{2}$ Assistant Professor, Department of Paediatrics, K.S. Hegde M edical Academy, Nitte University, \\ M angalore - 575 018, ${ }^{3,4}$ Professors, ${ }^{3}$ Department of Paediatrics, ${ }^{4}$ Department of Ophthalmology, \\ Kasturba Medical College M angalore, Manipal University, M angalore - 575 002, Karnataka, India. \\ Correspondence : \\ Rathika D. Shenoy \\ Professor, K. S. Hegde Medical Academy, Nitte University, M angalore - 575 018, Karnataka, India. \\ Mobile : +91 9448149795 E-mail : drshenoy2001@ hotmail.com
}

\begin{abstract}
:
We report on a child with M arinesco-Sjögren Syndrome, a rare autosomal recessive disorder characterised by early onset cataract, psychomotor delay, cerebellar hypoplasia and myopathy. The presentation, neuro-imaging and muscle biopsy features are discussed.
\end{abstract}

Keywords: Cerebellar hypoplasia; Growth failure; Hypotonia; M yopathy

\section{Introduction:}

Pediatric cataracts occur in isolation or in association with intra uterine infections, large number of metabolic diseases and genetic syndromes. Most present within infancy and only about one-fourth present in the second year of life or later. Bilateral cataracts in comparison with unilateral are especially associated with a systemic aetiology even if there are no discerning features. ${ }^{1}$ Marinesco-Sjögren Syndrome (MSS), inherited as an autosomal recessive disorder, is rare and is characterised by early onset cataract, psychomotor delay, cerebellar hypoplasia and myopathy. We report on a child with MSS, where the diagnosis was initially overlooked as the psychomotor delay was attributed to visual handicap and psychosocial deprivation.

\section{Case Report:}

A five year old male was seen as emergency consult for respiratory distress following reversal of general anaesthesia for cataract aspiration and intra-ocular lens

\begin{tabular}{|c|}
\hline Access this article online \\
\hline Quick Response Code \\
\hline
\end{tabular}
implantation. A medical clearance had been obtained prior surgery. He was the first born of third degree consanguinity. In addition to progressive diminution of vision and bilateral white reflex in the eyes since six months, he had global developmental delay which was not evaluated. Head control was achieved at eight months of age and sitting without support at three years. Presently he was able to bring himself to standing position and walk with support. His fine motor and social skills were delayed and speech unclear. There was no history of seizures. Pregnancy and birth history were normal. Though his birth weight was at the $75^{\text {th }}$ centile, his present growth parameters were below third centiles suggesting a post natal growth failure. Cataract was noted in the left eye and an intra-ocular lens in the right. There was no facial dysmorphism. Child had generalised hypotonia with diminished power and deep tendon reflexes. A detailed neuro-developmental evaluation was done after recovery. There was truncal ataxia, past pointing and dysarthria. His developmental age was one year and he walked with support with a waddling gait. Gower sign was negative and there was no calf muscle hypertrophy. Magnetic Resonance Imaging (M RI) of the brain showed cerebellar hypoplasia with small cerebellar hemispheres and prominent folia (Figure 1A, B and C). A literature search guided us in further neuromuscular evaluation. Muscle enzymes, serum aspartate aminotransferase (37IU/I) and creatine phosphokinase (92 IU/I) were within reference ranges; electomyogram demonstrated myopathic pattern. Nerve conduction studies, electro and echocardiogram 
were normal. Histological features of muscle biopsy under light microscopy suggested myopathy with minimal dystrophic changes (Figure 2A, B and C). Skeletal muscle was fairly preserved in architecture with focal adipose tissue infiltration. Variation in myofibre size with atrophic and hypertrophic fibres, focal myophagocytosis and polyfocal regenerating fibres were seen. Foci of endo and perimyseal perivascular lymphocytic infiltration with mild creeping fibrosis were present. The two year old younger sibling had global delay and hypotonia with no cataract. Parents were not willing for her evaluation.
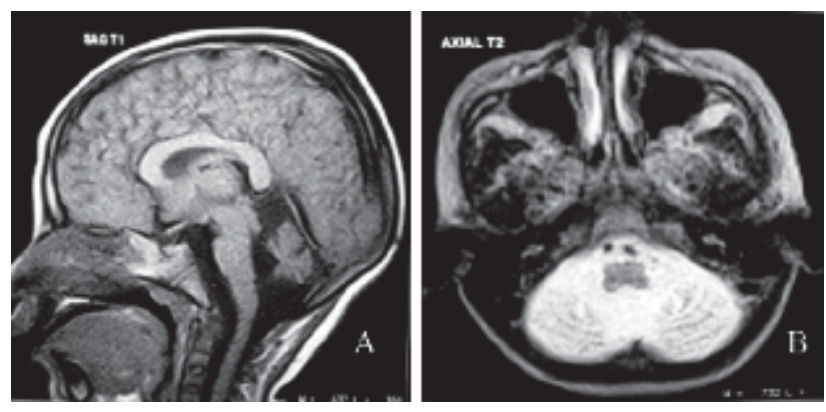

Figure 1: MRI Brain A. Sagittal midline T1 weighted image shows small cerebellar hemispheres with prominent fourth ventricle, prepontine and cerebello pontine cisterns B. Hyperintense cerebellar hemispheres on T2 with prominent folia C. Hyperintense left lens on $T 2$ image
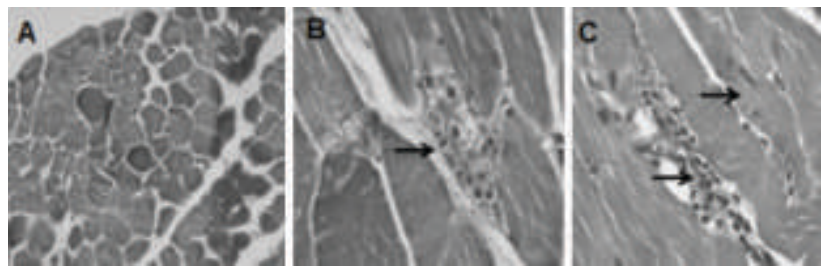

Figure 2: M uscle Biopsy showing: A. Variations in muscle fibre size B. Focal myophagocytosis C. Regenerating fibres with lymphocytic infiltration

\section{Discussion:}

In a child with developmental delay and bilateral cataract a careful history and examination will assist in etiological diagnosis. The differential diagnosis in a child with cataract, developmental delay, hypotonia and cerebellar signs is

\section{References:}

1. Krishnamurthy R, Vanderveen DK. Infantile cataracts. Int Ophthalmol Clin 2008; 48(2): 175-92.

2. Anttonen AK, Lahesjoki AE. GeneReviews: Marinesco-Sjögren syndrome. Available at: http://www.ncbi.nlm.nih.gov/books/ NBK1192/. Accessed on: 19.02.2011.

3. Kalaydjieva L. Congenital cataracts-facial dysmorphism-neuropathy. Orphanet Journal of Rare Diseases 2006; 1:32. limited. M SS as originally described by M arinesco in 1931 and Sjögren in 1950 included the triad of early onset cataracts, slowly progressive cerebellar ataxia and mental deficiency. Additional features subsequently described include growth failure, muscular hypotonia in early infancy, myopathy and skeletal abnormalities. ${ }^{2}$ Congenital Cataract, Facial Dysmorphism, and Neuropathy syndrome (CCFDN) is a distinct genetic entity but with clinical overlap. ${ }^{2,3} \mathrm{M}$ ajor differences between the two include marked cerebellar atrophy and myopathy in MSS and facial dysmorphism, micro cornea and demyelinating neuropathy in CCFDN. The molecular basis of MSS was established only in 2005 and SIL1 is the only gene known to be associated with it. ${ }^{4}$

In MSS muscular hypotonia and psychomotor delay precede cerebellar signs and cataract development. $M$ yopathy is the most important cause of delayed motor development in these children and may remain largely unrecognised because of the cerebellar involvement. Progressive myopathy involving posterior thoracic, pelvic, thigh and leg muscles with severe clinical disability has been demonstrated in homozygous patients by muscle computed tomography. ${ }^{5}$ Our child was investigated for myopathy in spite of normal muscle enzymes following literature search. The dystrophic changes seen in the muscle biopsy in our case has been reported by others also. ${ }^{6,7}$ In young patients auto phagocytosis is minimal, resembling the findings in progressive muscular dystrophy. ${ }^{7}$ The cataract is usually early onset by second year of life and not necessarily congenital. Most children require surgery for cataract by end of first decade. Problems during anaesthesia have been described with both M SS and CCFDN and need to be anticipated ${ }^{3.8}$ Current data indicate that patients survive well into adulthood with motor function stabilising at an unpredictable age and degree of severity.

4. Senderek $J^{1}$, Krieger M, Stendel C, Bergmann C, Moser M, BreitbachFaller N, Rudnik-Schöneborn S, Blaschek A, Wolf NI, Harting I, North K, Smith J, Muntoni F, Brockington M, Quijano-Roy S, Renault F, Herrmann R, Hendershot LM, Schröder JM , Lochmüller H, Topaloglu H, Voit T, Weis J, Ebinger F, Zerres K.. M utations in SIL1 cause M arinescoSjögren syndrome, a cerebellar ataxia with cataract and myopathy. Nat Genet 2005; 37: 1312-4. 
5. Mahjneh $I^{1}$, Anttonen AK, Somer $M$, Paetau A, Lehesjoki AE, Somer $H$, Udd B.Myopathy is a prominent feature in Marinesco-Sjögren syndrome: A muscle computed tomography study. J Neurol 2006; 253(3): 301-6.

6. Tachi N, Nagata N, Wakai S, Chiba S. Congenital muscular dystrophy in M arinesco-Sjögren syndrome. Pediatr Neurol 1991; 7(4): 296-8.

7. Goto Y, Komiyama A, Tanabe Y, Katafuchi Y, Ohtaki E, Nonaka I. $M$ yopathy in Marinesco-Sjögren syndrome: an ultrastuctural study. Acta Neuropathol 1990; 80(2): 123-8.

8. M inami K, Sata T, Shigematsu A. General anaesthesia for M arinescoSjögren syndrome.J Anesth 1994; 8(2): 224-6. 